\title{
Putting (Human) Communication at the Center of Technology Studies
}

\author{
Erin K. Ruppel
}

University of Wisconsin Milwaukee

Communication technologies such as the Internet, interpersonal messaging applications, and social media are embedded in our lives in both obvious and nonobvious ways. A recent Pew survey found that $81 \%$ of U.S. adults report going online at least daily, and 28\% say that they are online "almost constantly" (Perrin \& Kumar, 2019). Even more traditional mass media such as television and radio are often accessed via Internet-enabled websites and applications (e.g., Netflix, Spotify). Mobile connectivity in the form of smartphones has further changed the landscape of technology-mediated communication by creating "hybrid spaces" in which users can combine face-to-face and mediated interaction (Campbell, 2019, p. 55). Between 2011 and 2019, the percentage of U.S. adults who own a smartphone increased from $35 \%$ to $81 \%$, with $37 \%$ of the sample primarily going online via their smartphone (Anderson, 2019). Similarly, in a 2019 survey of 11 emerging-economy countries, a median of 53\% of adults owned a smartphone (Silver et al., 2019). Increasing mobile connectivity has made of communication technology infrastructure less visible (Meyer, Schroeder, \& Cowls, 2016), and access to communication technologies has become "socially ingrained" in our lives (Ling, 2012, p. 4).

In a 2009 special section of Journal of Computer-Mediated Communication, Malcolm Parks discussed the impending invisibility of communication technologies in our lives and asked, "What will we study when the Internet disappears?" (2009, p. 724). His answer was that if we want to continue to better understand technology-mediated communication even as it becomes more ingrained in our everyday lives, we need to emphasize the "fundamental communicative processes involved" in that communication (Parks, 2009, p. 725). The diffusion of mobile connectivity and proliferation of Internet-enabled computer and smartphone applications in the decade since Parks's essay was published has arguably increased the need for communication-focused technology research. However, progress in this area has been slow. Research on communication technologies is largely atheoretical and focused on individual media instead of the broader context in which technology-mediated communication occurs. Further, most communication technology journals are primarily psychological or interdisciplinary, as opposed to being explicitly focused on communication. The addition of a communication-focused journal such as Human Communication \& Technology can help address these

CONTACT Erin K. Ruppel ruppele@uwm.edu Department of Communication, University of WisconsinMilwaukee, 2522 E. Hartford Ave., Milwaukee, WI 53201, USA 
shortcomings of current research and, as a result, advance not only the field of technology studies but also the field of communication as a whole.

Communication technology research has often been criticized for failing to incorporate relevant theory. For example, a review of published literature on communication technologies between 1998 and 2013 found that only 30\% of articles used a specific theory (Borah, 2017). This finding is consistent with that of an older review, which found that only $31 \%$ of Internet studies articles published between 2000 and 2009 were theoretically-oriented (Peng, Zhang, Zhong, \& Zhu, 2013). Walther (2009) observed that even when research uses theory, it has failed to adequately test the boundary conditions of the theories being used. Better utilizing and testing theory can help guide our hypotheses, make sense of our findings, and as a result, drive research forward. In particular, there seems to be a gap between communication technology studies and more traditional communication theories that is just beginning to be filled. While we need more research that uses communication-focused technology theories, understanding the communication processes that occur when we engage in communication via technologies also requires re-examining more traditional communication theories to understand how those theories might inform or be informed by communication technology use.

Employing theories in our study of communication via technologies also allows us to better understand the context in which communication technologies are used. In many cases, we cannot fully understand how and why people use communication technologies, and with what effects, without understanding the broader social or relational landscape in which that use occurs. For example, understanding the implications of relational talk about certain topics via technologies requires knowing how partners talk about those topics face-to-face (Caughlin \& Sharabi, 2013). Further, use of one communication technology is often associated with the use of other communication technologies, and these associations can vary based on individual or relational factors (Ruppel \& Burke, 2015; Ruppel, Burke, \& Cherney, 2018). Despite the growing acknowledgement that communication technologies are embedded in the larger communication context of people's lives and relationships, over time, research has trended more toward studying specific technologies, such as social networking sites or video games (Borah, 2017). In some cases, research focuses even more narrowly on specific platforms such as Facebook (Rains \& Brunner, 2015). Focusing on individual technologies or platforms, some of which have become or will become obsolete, limits researchers' abilities to understand the broader communication context in which technologies are used and build on previous findings to continue advancing communication technology theory.

As the field of communication technologies continues to develop, research will become more specialized (Meyer et al., 2016). Although interdisciplinary journals are beneficial for bringing together researchers and ideas across disciplines, we also need journals that can speak directly and specifically to ways in which communication processes affect technology use, and vice versa. Communication-focused technology journals provide not only an outlet for communication-focused research but also a source of research findings and knowledge for scholars in other fields who aim to study communication technologies. The field of communication is uniquely situated to understand how people use technologies, particularly as 
communication technology research continues to develop. For example, the examination of masspersonal communication, enabled by communication technologies, is informed by the study of both mass communication and interpersonal communication (O'Sullivan \& Carr, 2018). Although the idea of overlap between mass and interpersonal communication has been around for over 30 years (e.g., Gumpert \& Cathcart, 1986; Reardon \& Rogers, 1988), progress in developing theoretical and methodological frameworks that utilize this overlap has been slow. This issue is arguably due, in part, to the tendency to focus on specific technologies, instead of the communication that occurs within them. By embracing specialization and privileging communication in our study of technologies, we can uncover overlaps that are less apparent to other disciplines and create conceptual frameworks that will allow us to advance research in cumulative and theoretically grounded ways

Fundamentally, human communication and the mode by which it occurs (e.g., face-to-face, text message, social media, phone call, or even carrier pigeon) are inextricably linked. The messages we send are embedded in the communication modes via which they are sent (Ledbetter, 2014). Understanding communication therefore requires an understanding of the modes via which it occurs. Further, understanding communication modes requires understanding the communication that occurs within them. To adequately conceptualize and model communication processes, we need to attend to both the communication that occurs and the modes via which it occurs - whether that is face-to-face, via communication technologies, or some combination of the two. Human Communication \& Technology will help provide space for research that will drive the field of communication technologyand the field of communication more generally - forward via communication-focused, theoretically-driven research.

\section{References}

Anderson, M. (2019). Mobile technology and home broadband 2019. Retrieved from Pew Research Center website: https://www.pewinternet.org/2019/06/13/mobile-technology-and-home-broadband-2019/

Borah, P. (2017). Emerging communication technology research: Theoretical and methodological variables in the last 16 years and future directions. New Media E Society, 19, 616-636. https://doi.org/10.1177/1461444815621512

Campbell, S. W. (2019). From frontier to field: Old and new theoretical directions in mobile communication studies. Communication Theory, 29, 46-65. https:// doi.org/10.1093/ct/qty021

Caughlin, J. P., \& Sharabi, L. L. (2013). A communicative interdependence perspective of close relationships: The connections between mediated and unmediated interactions matter. Journal of Communication, 63, 873-893. https://doi. org/10.1111/jcom.12046

Gumpert, G., \& Cathcart, R. (1986). The interpersonal and media connection. In G. Gumpert \& R. Cathcart (Eds.), Inter/media: Interpersonal communication in a media world (3rd ed., pp. 17-25). New York, NY: Oxford Univ. Press.

Ledbetter, A. M. (2014). The past and future of technology in interpersonal communication theory and research. Communication Studies, 65, 456-459. https:// doi.org/10.1080/10510974.2014.927298 
Ling, R. (2012). Taken for grantedness: The embedding of mobile communication into society. Cambridge, MA: The MIT Press.

Meyer, E. T., Schroeder, R., \& Cowls, J. (2016). The net as a knowledge machine: How the Internet became embedded in research. New Media \& Society, 18, 1159-1189. https://doi.org/10.1177/1461444816643793

O'Sullivan, P. B., \& Carr, C. T. (2018). Masspersonal communication: A model bridging the mass-interpersonal divide. New Media \& Society, 20, 1161-1180. https://doi.org/10.1177/1461444816686104

Parks, M. R. (2009). What will we study when the Internet disappears? Journal of Computer-Mediated Communication, 14, 724-729. https://doi.org/10.1111/j.10836101.2009.01462.x

Peng, T.-Q., Zhang, L., Zhong, Z.-J., \& Zhu, J. J. (2013). Mapping the landscape of Internet Studies: Text mining of social science journal articles 2000-2009. New Media \& Society, 15, 644-664. https://doi.org/10.1177/1461444812462846

Perrin, A., \& Kumar, M. (2019). About three-in-ten U.S. adults say they are 'almost constantly' online. Retrieved from Pew Research Center website: https://www.pewresearch.org/fact-tank/2019/07/25/americans-going-online-almost-constantly/

Rains, S. A., \& Brunner, S. R. (2015). What can we learn about social network sites by studying Facebook? A call and recommendations for research on social network sites. New Media \& Society, 17, 114-131. https://doi. org/10.1177/1461444814546481

Reardon, K. K., \& Rogers, E. M. (1988). Interpersonal versus mass media communication a false dichotomy. Human Communication Research, 15, 284-303. https://doi.org/10.1111/j.1468-2958.1988.tb00185.x

Ruppel, E. K., \& Burke, T. J. (2015). Complementary channel use and the role of social competence. Journal of Computer-Mediated Communication, 20, 37-51. https://doi.org/10.1111/jcc4.12091

Ruppel, E. K., Burke, T. J., \& Cherney, M. R. (2018). Channel complementarity and multiplexity in long-distance friends' patterns of communication technology use. New Media \& Society, 20, 1564-1579.

Silver, L., Smith, A., Johnson, C., Taylor, K., Jiang, J., Anderson, M., \& Rainie, L. (2019). Mobile connectivity in emerging economies. Retrieved from Pew Research Center website: https://www.pewinternet.org/2019/03/07/mobile-connectivity-in-emerging-economies/

Walther, J. B. (2009). Theories, boundaries, and all of the above. Journal of Computer-Mediated Communication, 14, 748-752. https://doi.org/10.1111/j.10836101.2009.01466.x 